\title{
The Arts and Humanities in Health Professional Education
}

Pam Harvey (Monash University), Neville Chiavaroli (University of Melbourne), Giskin Day (Imperial College London)

\section{Overview}

This chapter provides a perspective on clinical education through the lens of the humanities. It discusses enhancing clinical expertise by focusing learning on affective aspects of a learner's discipline, assisting their development as effective health professionals.

\section{Keywords}

Health humanities; humanities lens; phronesis; epistemological education

\section{Introduction}

The health humanities are an evolving area of scholarship and educational practice at the intersection of humanities and healthcare. It takes an interdisciplinary approach towards understanding the complexities of health and illness, the humanistic factors that influence the lived experience of those involved, and the contexts in which these occur. Education through the health humanities provides a way of making meaning using disciplines traditionally aligned with the arts and humanities, challenging notions that the necessary clinical skills of health 
professionals need only be learned through scientific knowledge and teaching clinical skills.

The health humanities are not new to health professional education. What began as 'medical humanities', and became more inclusive of other health disciplines (1), is now part of the curriculum of many health professional schools, either integrated into core curricula or offered as an elective. The health humanities promised to assist learners to better manage the challenges and uncertainties of health practice through educational experiences that reflect the kinds of reasoning which underlie good clinical practice (2).

\section{The Health Humanities perspective}

\section{A clinical encounter}

Fourth year undergraduate medical student, Dana, is on the medical ward under the supervision of a registrar. Dana prepared to present Mrs Thelma Bright to her clinical supervisor the following information:

Mrs Thelma Bright is a seventy-eight-year-old woman admitted yesterday after a fall at home. She was discovered by a neighbour after failing to bring in her recycling bins. It is estimated that Mrs Bright was not found for 24 hours after her fall. Ambulance officers responded to the neighbour's telephone call and presented to the rural town 45 minutes later. Mrs Bright was assessed as responsive, with a Glasgow Coma Scale reading of 11. There was obvious deformity in her right wrist. She was transferred to a regional hospital and diagnosed with a right fracture of the radius and ulna, dehydration and cachexia. Her wrist was immobilised and she 
responded to treatment in the emergency department, with her GSC revised to 13. Co-morbidities include Type II diabetes, diverticulitis and early stage dementia.

In Mrs Bright's notes, Dana discovered an advanced care plan in her records that stated she wanted medical treatment only if it would sustain her current quality of life. Her substitute decision maker was listed as a son who was unable to be present until the next day. There were no other contacts listed in her record. A previous occupational therapy visit to her home reported that there were multiple safety concerns in Mrs Bright's house but, at the time, a cognitively competent Mrs Bright had refused any modifications.

As Dana stood at the nurse's station reading these notes, Mrs Bright began to call out for pain relief. Dana notified a nurse who said pain relief was not due for another two hours. An emergency call was made to another bed, and staff became busier. Mrs Bright was still yelling when Dana's supervisor returned but Dana felt unable to mention her concerns until the registrar had attended to other patients. 'She's had all the pain management possible for the moment,' the registrar said. 'She'll just have to cope.'

Dana left the ward to attend tutorials and didn't return until the next day. Overnight, Mrs Bright had a cardiac arrest and the team interpreted her written wishes as 'no CPR'. Mrs Bright died shortly before Dana arrived. As Dana stood with the nurses at the central station, Mrs Bright's son arrived looking flustered. Although he was taken to a private interview room, Dana could still hear him reacting angrily to news of his mother's death. The registrar shrugged when Dana looked at him. 'It's difficult,' he 
said, rubbing his face with his hand. 'I might react the same way if it was my mother in there.'

Dana remained at the desk as the son came out and went into his mother's room, emerging two minutes later and leaving the ward. She could see the corner of Mrs Bright's bed and a nurse beginning to take care of the body. This was not how she imagined the care of a patient would go and she didn't know how to feel.

\section{The humanities lens}

The above fictional case is an amalgamation of student experiences, but the presentation of Mrs Bright fits a typical standard medical paradigm. The patient is presented as a biomedical 'problem' - a case of loss of consciousness, for which there are several possible differential diagnoses and underlying causes. The broken wrist complicates this presentation, as do other comorbidities. While the hospital team is presented as focussing on Mrs Bright's immediate medical needs (restoration of full consciousness and stabilisation of her fracture), Dana is portrayed as noticing important aspects, empathising, and struggling to process several ethical, professional and psychosocial aspects of Mrs Bright's care. While this vignette was created specifically for the purposes of this chapter, this tension is by no means uncommon for medical and healthcare students $(3,4)$.

Such tensions offer important opportunities for a humanities-related perspective on medical and health professional training. Dana's discovery of the advanced care plan (ACP) raises important considerations - ethical, functional (that is, determining quality of life), social and legal issues which require understanding beyond 
biomedicine and clinical procedures. Mrs Bright's previous refusal to allow modifications to her home might also raise further medicolegal and psychosocial issues (for example, regarding her cognitive functioning) which could influence how the ACP is interpreted and acted upon.

Dana's communication and articulation of her concerns to the hospital staff (including her own supervisor) introduces important system-level issues, complicated by Dana's status as a medical student. While the decision to hold off further pain management may well be defensible from a medical perspective, Dana's instinctive empathy is to be commended. Clearly, broader ethical and professional issues remain over how well the health system manages high quality, compassionate care during busy periods, both in this case and more generally. Finally, from a pedagogical and professional development perspective, Dana's presence during the unfolding of the situation clearly presents a significant learning moment for her, and the scholarly literature is increasingly clear that these are moments can be critical for students' professional identity formation (4-7). The supervisor's frank admission in relation to the son is commendable and could provide an important example of humanistic concern and empathy for Dana.

There is no doubt that many clinical supervisors are instinctively attuned to these sorts of challenges and teaching moments, and can and do assist health professional students through them. These moments are not always reflected in the taught or formal curriculum, which we now know can have major implications for how such affective and professional matters are perceived by students and supervisors alike $(8,9)$. A number of teachers and practitioners of the health humanities have 
presented detailed and passionate rationales as to how humanities content, methods, and/or perspectives can facilitate student learning in medical and health professional education (10-15). Many go further to argue that the humanities can help students to learn to prepare for clinical placements and to learn to know and think like clinicians, drawing on the humanities' content and methods which emphasise and explore the ambiguous, the experiential, the particular, and the qualitative aspects of phenomena as a complement to the more positivistic and generalisable knowledge and ways of thinking of the bioscientific and clinical foundations of medicine. Such claims can be described as 'epistemological', and we will explore these further in the next section.

Specifically, a humanities-informed perspective could have helped an educator focus on both the broader professional aspects and clinical complexities of the situation, including:

- Dana's thoughts and uncertainty about the status and impact of the advanced care plan;

- Dana's concerns about Mrs Bright's pain (and lack of response of the staff);

- Dana's inability to bring the full extent of her concerns to the registrar's attention;

- her status on the ward as a medical or health professional student;

- Dana's struggle to understand the clinical management priorities of the staff;

- the difficulty of communicating bad news to family and the challenge of dealing with their response; and

- the emotional impact of the whole event on Dana, as a medical student and as a fellow human being. 
While some of the above clearly involve specific clinical and medical features of Mrs Bright's condition and situation, the majority concern affective aspects of a student's learning and development as a professional, such as Dana's final reflection on how events unfolded for Mrs Bright. Therefore, they are likely not very amenable to didactic or clinically-oriented responses by clinical supervisors; as deeply personal, emotional and 'embodied' experiences (16), approaches which value and explore empathy and understanding of patients' perspective would seem to be more useful here. The humanities can help clinicians tap into this level of response.

Let us leave Dana for now and turn to consider the status of health humanities in health and medical education.

\section{Why the health humanities?}

The inclusion of the study of humanities in health professional curricula has had an uneven trajectory. Its successes have depended on the curriculum policies of individual medical schools, and often the enthusiasm of individuals willing to make a case for curriculum change. Fox has traced the origins of the medical humanities in the United States to a 1960s campaign for courses in 'human values in medicine' (17). In the United Kingdom, the General Medical Council's 1993 guidelines for outcomes for medical education (18) gave an impetus to the field when stating that arts and humanities be included in special-study options that were to make up a third of the undergraduate curriculum. Since the 1990s, courses have been offered in Australia and New Zealand, as well as many countries across Europe. An account of the development of medical humanities in Hong Kong, Taiwan and China is given by Wu and Chen (19), and initiatives in India are described by Shankar (20). Initiatives 
in Africa are described in a special issue of the journal Medical Humanities (21). In spite of these initiatives, Dana would have been unlikely to have had exposure to humanities-type teaching at medical school. She may have been offered the opportunity to do a module in medical history or medicine and literature, but these are likely to have been optional on top of an already busy curriculum, or offered in competition with more apparently medically 'useful' courses.

Journals, books and medical humanities associations report a plethora of case studies on teaching humanities for students in medicine, nursing, dentistry, pharmacy and allied professions. As Ousager and Johannessen have pointed out in their literature review of humanities in undergraduate education, many reports are descriptive of teaching models and justifications, rather than demonstrations of impact (22). The case for making space for the arts and humanities in already crowded curricular tends to be based on arguments that biomedical education is reductionist and in danger of de-personalising medicine. The humanities are often construed as a corrective to a curriculum that trains doctors to be diagnostically skilled but uninspired, focused on treating diseases rather than healing individuals.

Another trend gaining traction is for the term 'medical humanities' to be replaced, or supplemented, with 'health humanities' (1). The word 'medical' is argued to be insufficiently inclusive of allied health professionals, informal caregivers, patients and those focused on health and wellbeing rather than just medical care $(23,24)$. Indeed, the humanities have been active in health professional teaching well before the name change (25-28). The International Health Humanities Network, funded mainly by the Arts \& Humanities Research Council, is the nexus for this contemporary interdisciplinary work. 
Whilst few would argue that biomedical sciences are devoid of imagination and creativity, the case is often made that pedagogy in the sciences emphasises the internalising of bodies of knowledge by students rather than grappling with concepts such as uncertainty, lived experience and the contextual contingencies of medicine (29). It is not surprising, then, that humanities and the arts, in which the emphasis is often on process - interpretation, acknowledgement of subjectivity, critical reflection - are seen as adjunct to the sciences.

Whilst undoubtedly successful in gaining a foothold for the humanities in medical curricula, this complementary approach has been criticised for failing to 'disrupt an intellectual economy in which all animating liveliness is accrued by the humanities, and all hard-nosed scientific expertise by the biomedical sciences' (30). Research into the intellectual underpinnings of the culture, social and historical dimensions of medicine received a major boost in 2008 in the UK when the Wellcome Trust announced expanded funding streams for the medical humanities. Under the umbrella of the 'critical medical humanities', spearheaded by the Institute for Medical Humanities at Durham University, UK, proponents call for disciplinary 'entanglement', rather than the hitherto dominant ideology of 'integration' of humanities and medical science.

As alluded to earlier, an important rationale for the humanities in health professional education can be considered 'epistemological', in the sense of helping students (and practitioners) to learn and better understand how to think like a clinician. Such a view goes beyond the traditional rationales for the medical/health humanities that offered essentially intrinsic or instrumental rationales for the field. Rather, it focuses on the required knowledge, reasoning and thinking practice that makes for good clinical 
practice $(2,14,31-33)$. This involves much more than science-based knowledge or logico-deductive reasoning, as Montgomery argues in her influential book 'How Doctors Think' (2006). Clinical reasoning, she writes, is 'flexible, interpretive, ineradicably practical'. For Kumagai (2017), such reasoning involves 'encouraging engagement with complexity and ambiguity; seeing past the surface to historical and societal influences and causes; and encouraging an awareness of the multiple, unique voices and perspectives of patients'. Such an approach applied to clinical education, we suggest, would be more educationally meaningful and personally supportive than one aimed at simply helping students understand the clinical details of patient presentations or learn their place in the health system as a medical student.

Such epistemological considerations draw on a relatively long tradition in educational philosophy and the humanities of distinguishing between the idiographic and the nomothetic; or more simply, between the particular and the general. Biomedical knowledge privileges, indeed relies on, the latter, so that a medical treatment or clinical technique that works in one context is likely to generalise sufficiently to help other patients in a different context but with a similar condition. A good thing, too; health practice would be unsustainable if every case had to be approached from first principles every time. And yet, in some ways, every patient must be approached anew, at least from a holistic and patient-centred paradigm. This is where the humanities are a vital part of a health professional education. The humanities privilege the particular, the 'individual and contextual factors that make a particular situation or experience qualitatively different from another' $(32,34)$. Different patients may share the same disease, but as the revered Canadian medical educator William 
Osler (1849-1919) sagely noted long ago, 'it is much more important to know what sort of a patient has a disease than what sort of a disease a patient has'.

Aristotle has bequeathed an Ancient Greek concept for such situationally-sensitive clinical perspective - phronesis, or 'practical wisdom'. Many scholars and practitioners alike regard this as the essence of clinical practice: being able to recognise and incorporate the contextual, situational and particular aspects of a presentation, while drawing on the clinically relevant, generalisable aspects which will enable evidence-based management (35-38). As important as clinical guidelines and algorithms have been in standardising practice around the world, with indisputable improvements in certain patient outcomes, health practice which seeks to draw on an ethical, empathic and situationally-sensitive perspective of the patient remains the hallmark of professionalism (38). Phronesis, then, is the process of determining the appropriate action to take when 'knowledge depends on circumstance' (39). Health professionals should recognise in this phrase the very language frequently used in competency statements that purport to represent a profession's particular knowledge and competencies, or indeed, its epistemology. Consider how frequently the professions resort to phrases such as 'appropriate', 'relevant' and 'suitable' as indicators of, and placeholders for, clinical and professional judgement; necessarily so, since like algorithms, such statements can never capture the actual and myriad factors that go into making the right decision at the right time. It is the humanities, with its disciplines and methods focused on analysing, interpreting and understanding human personal and social experience, which can help train our minds to look for, and be sensitive to, data at this level. It is exactly the alternative perspective that scientific knowledge and reasoning needs to 
provide health practice with a balanced and complementary foundation of knowledge, reason and thinking.

So, let's return for a moment to Dana. We left her with particular dilemmas uncertainty about aspects of Mrs Bright's care, an inability to situate herself more powerfully on the ward as a team member, and the professional and personal challenges of highly emotive situations.

Applying a broader, humanities-oriented perspective to Dana's preparation for practice as a health professional student, her education so far may not have equipped her to cope with and learn from the reality of patient care and its accompanying affective impact. She has the clinical knowledge to accurately report Mrs Bright's presenting issues to the clinical supervisor, and to formulate Mrs Bright's management requirements. Tension was generated when Dana struggled to process the complex psychosocial and ethical aspects of the situation. Would the 'entanglement' (30) of the health humanities into her curriculum have given her strategies for enhanced clinical practice? We think so: but what would this education look like?

\section{Learning and teaching strategies}

If Dana's educators decided to modify the health professional curriculum by entangling the health humanities, they may have included material such as literature, visual arts or music. Applying another discipline's teaching paradigm into health professional education is not a new concept $(40,41)$ and is used with the 
expectation that the application of a different lens to education will enrich student learning and professional development.

There are a multitude of practical examples from the literature of teaching incorporating the arts and humanities, used in different ways and for different purposes. The following provide some ideas and strategies which health professionals may use in their teaching. Evaluating these strategies will depend on the contexts in which they are delivered.

\section{Close noticing}

The concept of 'close noticing' arises from the need for health professional to practice critical observation and notice their patients' presentation for diagnostic acumen (12). It focuses on health professionals' use of their senses and their ability to be sensitive (that is, ethically and humanely aware of a situation). Bleakley (2015) regards close noticing as the core of work done by artists and art critiques, making the techniques these professions use as highly suitable for the training of clinicians.

There have been visual arts-based educational programs reported in the health profession educational literature $(42,43)$. Many focus on improving the observational skills - the visual literacy - of health professional students, and also the ability to interpret and describe their observations. Others emphasise the development of empathy $(44,45)$ and communication skills. 
Borromeo et al report on a visual arts-based training program for dentistry students studying the management of special-needs patients (46). The program aimed to improve students' ability to notice relevant information, that is, to see behind clinically-focussed areas such as the mouth to the individual as a whole. Students participated in several two-hour sessions involving analytical observation of artworks in an art gallery space, and group discussions. At the send of these sessions, students reported that they had learned new skills in visual observation that they could apply to special-needs patients.

Naghshineh et al used an arts-observation teaching technique called Visual Thinking Strategies (VTS) with a group of medical students to develop critical thinking and communication skills, and improve visual literacy (47). Students were assigned either to be trained in this method or attend regular medical education sessions then tested against observational criteria. Students trained in VTS had improved observational skills. VTS has also been used for specific visual literacy needs such as improving clinical observation in dermatology (48).

What this training has in common is applying arts-based critical thinking to improve the critical reasoning of health professional students. Each involves 'close noticing' for meaning-making. The use of our senses, not only limited to sight, in clinical judgement is a professional aesthetic that Bleakley suggests would complement more strictly analytical decision-making methods (12).

\section{$\underline{\text { Close Reading }}$}


The term 'close reading' arises from literary scholarship and advocates close attention to more than the words in a text but also its tone, context and representation(49). For example, medical educator Rita Charon suggests that training in close reading assists the interpretation of all textual matter, from fiction to clinical artefacts such as X-rays (50). Developing this skill is part of narrative competence, or the ability to interpret the stories of the person and their illness within a situational context.

The use of literature in health professional courses has a history in the USA that dates back to the 1970s. The types of genres vary. Stories from patients (illness narratives or pathographies) and those from health professionals are common, particularly when the aim is to elicit responses about people's experiences of illness and healthcare. In the scholarly literature, there are recurring novels, short stories and poems that lend themselves to these experiences. The Doctor Stories by William Carlos Williams is frequently used as an example of the social barriers between the patient and their carers, and the experience of dying (51-53); as is Wit a play by Margaret Edson which has also successfully been adapted for film $(54,55)$.

By closely examining texts for their form and content, other elements are revealed. The act of reading itself is an active pursuit, as the reader interprets the text and creates meaning from it. In a sense, the reader uses cognitive and imaginative processes to position the text for understanding. The stories of Sherlock Holmes by Arthur Conan Doyle (a medical practitioner himself) have been used to study clinical reasoning (56); Aldous Huxley's Brave New World to study bioethics (57); and poems such as Raymond Carver's What the Doctor Said (58) can be used to 
examine patient-clinician relationships. The choice of text will depend upon the learning objectives of the session.

A growing genre of literature is the 'medical work memoir'. These are often didactic about lessons learned from experience making them attractive reads for students eager to benefit from the first-hand accounts of professionals. Henry Marsh's accounts of dealing with fallibility in brain surgery, Do No Harm(59) and Admissions(60), are popular choices. The story of Paul Kalanithi's transition from doctor to patient in When Breath Becomes Air(61) wrestles with issues of medical hierarchy and when 'too much information' becomes psychologically unhelpful. The Language of Kindness by nurse Christie Watson(62) gives an insight into the highs and lows of caring for patients at their most vulnerable. Adam Kay's 'secret diaries' of his medical training, This is Going to Hurt(63), is both extremely funny and very poignant. The study of medical memoirs, and extracts from them, provides an opportunity to discuss the ethical implications of writing about patients, e.g. when does a memoir have to be so heavily fictionalised to protect patient identities that it no longer becomes 'true'? At what point does writing about patients and colleagues become exploitative? Do candid errors admissions of medical mistakes damage public trust in medicine, or does honesty about medicine as a fallible enterprise serve as valuable reality check?

Close noticing and close reading are teachable skills if teachers themselves have strategies to do so. Having art and literature teachers involved in health professional education already occurs, particularly in universities that encourage interdisciplinary and inter-faculty collaboration. It is also possible for clinician-teachers to upskill in 
arts and humanities methods. Having broader capabilities as teachers may give health professional students more scope to manage the discomfort and ambiguity of healthcare.

The experience of exploring difficult issues associated with healthcare through close noticing and close reading in an educational setting opens opportunities for conversations with students about ethically fraught situations: conversations they may recall and draw on when faced with complex situations on the wards. Had Dana studied a text such as The Death of Ivan llych, a novella by Tolstoy, it may have resonated with her in the face of Mrs Bright's predicament. She may have recalled the loneliness felt by llych when his family appeared indifferent to his suffering. The story may have given Dana the confidence to approach Mrs Bright and offer solace by merely being a comforting presence. If the reading had been supplemented with, say, the writings of Atul Gawande - especially his book Being Mortal (64) - Dana might have felt less overwhelmed by the situation and more comfortable with end-of-life issues. Crucially, she would have had the opportunity to talk through concepts around quality of life in the care of the elderly so that she could feel better emotionally prepared to interact with Mrs Bright in a compassionate, humanistic way.

\section{Learning and practising empathy}

If we add to the practices of close noticing and close reading the idea of close listening, we approach the concept of empathy in health care, commonly defined as a multidimensional construct with cognitive, affective, behavioral and moral 
components(65). There was a time (especially in medical education and practice) when its value or appropriateness was debated, challenged by the alternate principle of 'clinical detachment'(66). These days such wariness tends to be negated by increasing evidence of the powerful therapeutic effects of clinical empathy(67), and thankfully rare but disturbing evidence of the opposite effect when health system factors lead to emotionally involved care $(68,69)$. In terms of both education and practice, empathy is today regarded as fundamental component of high quality and effective health care (67); yet, alarmingly, some evidence points to its decline through the course of training, across health professions(70-73) .

Importantly, then, one of the most consistent and particular claims of the medical/health humanities has been its capacity to promote and teach empathy to medical and health professional students $(66,74)$, and evidence is accumulating to support such claims, through the use of the various genres and methods representative of the humanities (75-81). Essentially, the humanities seek to understand human experience; in the context of health professional education, one of the most clinically useful and relevant applications of this is to help practitioners (and students) better attend to the patient's needs. This is more than just good communication skills, although undoubtedly important in themselves; genuine empathy helps the 'epistemological' focus of the clinical interaction $(32,82)$, encouraging and assisting the clinician to be mindful of, and seek to better understand, the patient's experience and perspective of their illness, and their particular social circumstances. We see this clearly in Dana's intuitive responses to Mrs Bright's situation and discomfort - her request for more pain medication, her focus on the son's reactions, her sense of emotional ambiguity at the end - all 
responses which, in the light of the above findings of empathy decline, take on a particular importance, and vulnerability. The imperative for clinical supervisors to nurture such instinctive responses, and help transform them into useful clinical learning experiences, cannot be over-estimated.

\section{The tolerance of ambiguity in healthcare}

Of related interest to health professional educators is how learners become comfortable accepting that ambiguity and uncertainty form much of the context in which healthcare occurs (83). Researchers have investigated whether this tolerance is an inherent characteristic of an individual, leading to them specialising in particular disciplines (84), or an attribute that can be enhanced with teaching. Tolerance of ambiguity is also associated with the development of empathy: and an increased empathetic response to challenging or ambiguous circumstances is a significant factor in healthcare communication (85).

In Dana's situation, ambiguity surrounded Mrs Bright's circumstances. The blackand-white application of healthcare principles, such as providing appropriate and effective pain management, did not seem to provide a solution. Instead, there was uncertainty as to why Mrs Bright had not responded; and the marginalisation of Dana's position as a member of the healthcare team. Her clinical supervisor, reacting to his own workload and supervisory pressures, had a less-than-empathetic response to Dana's concern, adding to her confusion. 
Tolerance of the grey-scale reality of healthcare is seen as an important skill, and one that can be taught through the health humanities. Visual skills training, for instance, has been used to not only improve visual literacy and observation skills, but also as an effective way for students to accept 'multiple meanings' of a situation (85), thus increasing their tolerance of ambiguity. Similarly, the development of narrative competence through close reading encourages health professionals to 'recognise, absorb, interpret, and be moved by the stories of illness' (50), approaching the uncertainty within the experience of illness with empathy and openness.

All of these different aspects of learning about clinical and/or health practice can be subsumed under the banner of professional formation. The humanities are focussed on and furnished with the particular methods and perspectives that help explore and understand human experience. This provides innumerable opportunities to think through and discuss collaboratively the kinds of issues and considerations which health professionals need to understand and manage on a daily basis. In this sense, the humanities provide a 'social laboratory' (or perhaps better, a collaboratory) for students to initially learn professionalism, safely and supportively, if set up and managed appropriately, before (or alongside) applying and translating such learning into the clinical setting. This sense of safety also applies to supervisors, and ultimately patients. A number of published resources provide examples and outlines of materials and methods which can be used or adapted to support a humanitiesbased professionalism curriculum, so we refer the reader to some of this literature(74, 86-91), and return to Dana to consider how the situation may have 
played out differently, from a humanities-informed and professional learning perspective.

\section{Unstructured learning moments}

What of Dana's workplace learning, the opportunities that the supervisor on the ward failed to seize in the face of Mrs Bright's death? Is the clinical placement, where theory and practice meld together to inform effective practice, a suitable location for the sensibilities of the health humanities?

In Dana's situation, the clinical supervisor had many opportunities to support and reinforce key professional learning. Dana was left with many uncertainties, some of which were exacerbated by her supervisor's responses. With humanities-based learning and a broader approach to supervision, could the learning experience have turned out differently for Dana?

We are not suggesting that the health humanities are a panacea for the complexities of health professional education. Imagine, though, if humanities-based perspectives such as close noticing and close reading had been an explicit part of the curriculum and clinical supervisor's training. Dana's dilemmas may have been recognised and addressed more clearly and explicitly. She queried Mrs Bright's pain management, not because she thought she had the decision-making power to give more pain relief, but because she was responding humanely to a person's cry for help. It may have been the case that Mrs Bright could not have had more medication, but that was probably not what Dana was thinking. She was bearing witness to a person's expressed pain, and then not being recognised as the witness. If the supervisor had 
noticed this, he may have given more thought to what his student was saying: how do we provide comfort to Mrs Bright? A response may have included clinical aspects of managing pain, but may have also addressed the role of a health professional in providing other care to Mrs Bright.

\section{A clinical encounter revisited}

Fourth-year undergraduate medical student, Dana, is on the medical ward under the supervision of a registrar. Dana prepares to present Mrs Thelma Bright to her clinical supervisor with a summary of information required for him to consider Mrs Bright's management. Once she has done that, Dana writes in her 'parallel chart' as encouraged by her supervisor, that is, her personal reflection of her encounter with Mrs Bright for later discussion:

Mrs Thelma Bright looks very frail and tiny in her bed. She's the same age as my grandmother so I was expecting someone as independent and strong as Granny. I can imagine how scary and painful it must have been for Mrs Bright to lie on the floor alone for so long. Her face is still pinched and she hardly opens her eyes so I wonder whether she knows where she is. Perhaps she still thinks she's on the floor of her home.

In Mrs Bright's patient record, Dana discovers an advanced care plan that stated Mrs Bright's wishes that she only wanted medical treatment if it would sustain her current quality of life. Considering that Mrs Bright had recently been living independently at home, Dana concludes that a good quality of life would mean the ability to return to as much independence as possible but wonders whether any health professional 
has talked this through with Mrs Bright. Real end-of-life care situations are new to Dana but she remembers being introduced to the topic through reading both clinical accounts and other literature in tutorial discussions. A critical reading of Being Mortal brought about discussions of contemporary medical practice and death and dying, informing Dana of the need to consider healthcare management, ethical concerns and a patient's wishes in the context of best care. That Mrs Bright's son was unable to be present until the next day understandably complicated matters.

As Dana is standing at the nurse's station reading these notes, Mrs Bright begins to call out for pain relief. Dana notifies a nurse who informs her that pain relief is not due for another two hours. Although Dana understands the pharmacological concerns, she thinks that Mrs Bright might find some consolation in someone sitting with her and perhaps acknowledging her suffering. When Dana's supervisor returns, he commends her compassion, recognises her concerns and says, 'Mrs Bright's had all the pain management possible for the moment but perhaps we could organise someone to spend some time with her. I will ask one of the nurses or arrange the chaplain to visit.'

Dana leaves the ward to attend tutorials and doesn't return until the next day. Overnight, Mrs Bright has a cardiac arrest and dies shortly before Dana arrives. As Dana stands with the nurses at the central station, Mrs Bright's son arrives looking flustered. Although he is taken to a private interview room to talk to the consultant, Dana could still hear him reacting angrily to news of his mother's death. She understands a bit more deeply how challenging delivering bad news is but understands and accepts the son's emotions while her supervisor explains the care 
Mrs Bright had received. Narrative competence was crucial in such a volatile situation as was close noticing, married with a high degree of empathy.

Dana remains at the desk as the son came out and went into his mother's room, emerging two minutes later and leaving the ward. She could see the corner of Mrs Bright's bed and a nurse beginning to take care of the body. Dana had never seen a real dead body but she had been involved in studying representations of death and dying through art. It struck her that health professionals had the opportunity to approach Mrs Bright's final moments with respect and dignity, and the solemnity the occasion deserved. Dana knew that she would still find the scene confronting but that her contribution to this aftercare was important.

When Dana meets her supervisor later that day, she has a number of questions for him, both clinical and professional. Alongside some of the biomedical management explanations of Mrs Bright's care, she is keener to understand how health professionals manage the ethical and emotional care of their patients and themselves, and how she could apply this to herself as she works towards becoming a qualified health professional

\section{Conclusion}

Dana's initial experience on the ward introduced some unintended consequences. The workplace, embroiled in busy-ness and process, was not something she had encountered before and her teaching to date had not provided her with tools or strategies to manage. The valuable learning opportunities that could have taken 
place were instead swamped by the struggle to balance teaching with a full clinical workload, a situation experienced by many clinician-teachers.

While the health humanities are not a panacea to the reality of workplace-based health professional education, they help better prepare a learner for the complexity of healthcare. While much teaching focuses on diagnosis and management, contemporary learners need more in their toolbox to work effectively with patients, carers and the rest of the healthcare team. Likewise, teachers and supervisors need a range of strategies to assist learners in developing in to competent health professionals. Entangling the health humanities into undergraduate, post-graduate and professional education, while being challenging, may well enhance clinical practice for the $21^{\text {st }}$ century.

\section{References}

1. Jones T, Blackie M, Garden R, Wear D. The almost right word: the move from Medical to Health humanities. Academic Medicine. 2017;92(7):932-5.

2. Boudreau JD, fuks A. The humanities in medical education: ways of knowing, doing and being. Journal of Medical Humanities. 2015;36(4):321-36.

3. Ginsburg S, Lingard L. 'Is that normal?' Pre-clerkship students' approaches to professional dilemmas. Medical Education. 2011;45:362-71.

4. $\quad$ Monrouxe LV, Rees CE, Endacott R, Ternan E. 'Even now it makes me angry': health care students' professionalism dilemma narratives. Medical Education. 2014:48:502-17.

5. Monrouxe LV, Rees CE. "It's just a clash of cultures": emotional talk within medical students' narratives of professionalism dilemmas. Advances in Health Sciences Education. 2012;17(5):671-701.

6. Kay D, Berry A, Coles NA. What experiences in medical school trigger professional identity development? Teaching and Learning in Medicine. 2018;31(1):17-25.

7. Lundin RM, Bashir K, Bullock A, Kostov CE, Mattick KL, Rees CE, et al. "l'd been like freaking out the whole night": exploring emotion regulation based on junior doctors' narratives. Advances in Health Sciences Education. 2018;23(1):7-28.

8. Hafferty FW, Franks R. The hidden curriculum, ethics teaching, and the structure of medical education. Academic Medicine. 1994;69(11):861-71. 
9. Martimianakis MA, Michalec B, Lam J, Carrie C, Taylor J, Hafferty FW. Humanism, the hidden curriculum, and educational reform: a scoping review and thematic analysis. Academic Medicine. 2015;90(11 Suppl):S5-S13.

10. Blease $\mathrm{C}$. In defence of utility: the medical humanities and medical education. Medical Humanities. 2016;42(2):103-8.

11. Tsevat RK, Sinha AA, DasGupta S. Bringing home the health humanities: narrative humilty, structual competancy, and engaged pedagogy. Academic Medicine. 2015;90(11):1462-5.

12. Bleakley A. Medical Humanities and Medical Education. London: Routledge; 2015.

13. Doukas D, McCullough LB, Wear S, Lehmann L, Nixon LL, Carrese J, et al. The challenge of promoting professionalism through medical ethics and humanities education. Academic Medicine. 2013;88(11):1624-9.

14. Kumagai AK. Beyond "Dr. Feel-Good": a role for the humanities in medical education. Academic Medicine. 2017;92(12):1659-60.

15. Chiavaroli N, Huang C-D, Monrouxe L. Learning Medicine With, From, and Through the Humanities: Evidence, Theory, and Practice. 2018. p. 223-37.

16. Shapiro L, Stolz SA. Embodied cognition and its significance for education. Theory and Research in Education. 2019;17(1):19-39.

17. Fox DM. Who we are: the political origins of the medical humanities.

Theoretical Medicine. 1985;6:327-42.

18. General Medical Council. Tomorrow's Doctors: recommendations on undergraduate medical education. London; 1993.

19. $W u \mathrm{H}$, Chen J. Conundrum between internationalisation and interdisciplinarity: reflection on the development of medical humanities in Hong Kong, Taiwan and China. MedEdPublish [Internet]. 2018; 7(46). Available from:

https://www.mededpublish.org/manuscripts/1920.

20. Shankar PR. Medical Humanities in Medical Schools in India. Archives of Medicine \& Health Sciences. 2016;4(2):166.

21. Various. Special issue: medical and health humanities in Africa - inclusion access and social justice. Medical Humanities. 2018;44(4).

22. Ousager $\mathrm{J}$, Johannessen $\mathrm{H}$. Humanities in undergraduate medical education: a literature review. Academic Medicine. 2010;85(6):988-98.

23. Crawford P, Brown B, Baker C, Tischler V, Abrams B. Health Humanities. Health Humanities. London: Palgrave Macmilla UK; 2015. p. 1-19.

24. Jones T, Wear D, Friedman LD. The why, the what and the how of the medical/health humanities. Health Humanities Reader. New Brunswick, USA: Rutgers University Press; 2014.

25. Parlow J, Rothman A. Attitudes towards social issues in medicine of five health science faculties. Social Science \& Medicine. 1975;8(6):351-8.

26. Neidle EA. Bringing humanities into dental education: a modest experiment. Mobius: A Journal for Continuing Eduction Professionals in Health Sciences. 1982;2(3):89-104.

27. Thow M, Murray R. Medical humanities in Physiotherapy: education and practice. Physiotherapy. 1991;77(11):733-6.

28. Bumgarner GW, Spies AR, Asbill CS, Prince V. Using the humanities to strengthen the concept of professionalism among first-professional year pharmacy students. American Journal of Pharmaceutical Education. 2007;71(2):Article 28. 
29. Day G. Establishing a pulse: arts for reflection, resilience, and resonance in STEM education. International Journal of Social, Political, and Community Agendas in the Arts. 2016;11(4):1-9.

30. Viney W, Callard F, Woods A. Critial medical humanities: embracing entanglement, taking risks. Medical Humanities. 2015;41:2-7.

31. Macnaughton J. The humanities in medical education: context, outcomes and structures. Medical Humanities. 2000;26:23-30.

32. Chiavaroli N. Knowing how we know: an epistemological reationale for the medical humanities. Medical Education. 2017;51:13-21.

33. Solomon M. Epistemological reflections on the art of medicine and narrative medicine. Perspectives in Biology \& Medicine. 2008;51(3):406-17.

34. Bruner J. Narrative and paradigmatic modes of thought. In: Eisner E, editor. Learning and teaching the ways of knowing. 84th Yearbook of the National Society for the study of Education. Chicago, USA: University of Chicago Press; 1985. 35. Chiavaroli N, Trumble S. When I say...phronesis. Medical Education. 2018;52(1005-1007).

36. Neighbour R. The Inner Physician: why and how to practice 'Big Picture Medicine'. London, UK: RCGP; 2016.

37. Davis FD. Phronesis, clinical reasoning, and Pellegrino's philosophy of medicine. Theoretical Medicine. 1997;18(1-2):173-95.

38. Phronesis as Professional Knowledge: practical wisdom in the professions. Rotterdam: Sense Publishers; 2012.

39. Montgomery K. How doctors think: Clinical judgment and the practice of medicine. New York, NY: Oxford University Press; US; 2006.

40. Lake J, Jackson L, Hardman C. A fresh perspective on medical education: the lens of the arts. Medical Education. 2015;49(8):759-72.

41. Jones EK, Kumagai AK, Kittendorf AL. Through another lens: the humanities and social sciences in the making of physicians. Medical Education. 2019;53(4):32830.

42. Braverman IM. To see or not to see: how visual training can improve observational skills. Clinical Dermatology. 2011;29(3):343-6.

43. Boisaubin EV, Winkler MG. Seeing patients and life contexts: the visual arts in medical education. The American Journal of the Medical Sciences. 2000;319(5):2926.

44. Sampson S, Shapiro J, Billimek J, Shallit J, Youm J. Medical student interpretation of visual art: who's got empathy? MedEdPublish [Internet]. 2018; 7(3):[68 p.].

45. Yang K-T, Yang J-H. A study of the effect of a visual arts-based program on the scores of Jefferson scale for physician empathy. BMC Medical Education. 2013;13(142).

46. Borromeo M, Gaunt H, Chiavaroli N. The Visual Arts in Health Education at the Melbourne Dental School. In: McLean CL, editor. Creative Arts in Humane Medicine. Canada: Brush Education Inc; 2014. p. 40-55.

47. Naghshineh S, Hafler JP, Miller AR, Bianco MA, Lipsitz SR, Dubroff RP, et al. Formal art observation training improves medical students' visual diagnostic skills. Journal of General Internal Medicine. 2008;23(7):991-7.

48. Gurwin J, Revere K, Niepold S, Bassett B, Mitchell R, Davidson S, et al. A randomized controlled study of art observation training to improve medical student ophthalmology skills. Ophthalmology. 2018;125(1):8-14. 
49. Shapiro J, Nixon LL, Wear SE, Doukas DJ. Medical professionalism: what the study of literature can contribute to the conversation. Philosophy, Ethics, and Humanities in Medicine. 2015;10:1-8.

50. Charon R. Narrative medicine: Honoring the stories of illness. New York, NY: Oxford University Press; US; 2006.

51. McLennan MF. Literature and medicine: some major works. Lancet. 1996;348:1014-6.

52. Charlton B, Verghese A. Caring for Ivan Ilyich. Journal of General Internal Medicine. 2010;25(1):93-5.

53. Williams WC. The Doctor Stories. USA: New Directions Books 1984; 1932.

54. Gottlieb CM. Pedagogy and the art of death: reparative readings of death and dying in Margaret Edson's Wit. Journal of Medical Humanities. 2018;39(3):325-36.

55. Shapiro J. Commentary on Wit. Academic Medicine. 2016;91(11):1523.

56. Montgomery K. Sherlock Holmes and Clinical Reasoning. In: Hunsaker Hawkins A, Chandler McEntyre M, editors. Teaching Literature and Medicine. New York: The Modern Language Association; 2000. p. 299-305.

57. Yates Stripling M. Bioethics and Medical Issues in Literature. USA: University of California Medical Humanities Press; 2013.

58. Carver R. What the Doctor Said. Academic Medicine. 2008;83(4):420.

59. Marsh H. Do no harm: stories of life, death and brain surgery. London: Weidenfeld \& Nicolson; 2014.

60. Marsh H. Admissions: a life in brain surgery. London: Weidenfeld \& Nicolson; 2018.

61. Kalanithi P. When breath becomes air: what makes life worth living in the face of death. London: Vintage; 2016.

62. Watson $\mathrm{C}$. The language of kindness: a nurse's story. London: Chatto \& Windus; 2018.

63. Kay A. This is going to hurt: secret diaries of a junior doctor. London: Picador; 2018.

64. Gawande A. Being Mortal. London: Wellcome Collection; 2015.

65. Jeffrey D. Clarifying empathy: the first step to more humane clinical care.

British Journal of General Practice. 2016;66(643):e143-e5.

66. Garden RE. The problem of empathy: medicine and the humanities. New Literary History. 2007;38(3):551-67.

67. Hojat M. Empathy in health professions education and patient care: Springer International Publishing; 2016.

68. Weir JM, Aicken MD, Cupples ME, Steele K. From Hippocrates to the Francis report - reflections on empathy. Ulster Medical Journal. 2015;84(1):8-12.

69. Halligan A. The Francis report: what you permit, you promote. Journal of the Royal Society of Medicine. 2013;106(4):116-7.

70. Sherman JJ, A. C. Measurement of changes in empathy during dental school. Journal of Dental Education. 2005;69:338-45.

71. Neumann M, Edelhauser F, Taushel D, Fischer MR, Wirtz M, Woopen C, et al. Empathy decline and its reasons: a systematic review of students with medical students and residents. Academic Medicine. 2011;86(6):996-1009.

72. Nunes P, Williams S, Sa B, Stevenson K. A study of empathy decline in students from five health disciplines during their first year of training. International Journal of Medical Education. 2011;2:12-7. 
73. Ward J, Cody J, Schaal M, Hojat M. The empathy enigma: an empical study of decline in empathy among undergraduate nursing students. Journal of Professional Nursing. 2012;2012:28-34.

74. Jones T, Wear D, Friedman LD. Health Humanities Reader. New Brunswick, New Jersey and London: Rutgers University Press; 2014.

75. Darbyshire P. Understanding caring through arts and humanities: a medical/nursing humanities approach to promoting alternative experiences of thinking and learning. Journal of Advanced Nursing. 1994;19(5):856-63.

76. Graham J, Benson LM, Swanson J, Potyk D, Daratha K, Roberts K. Medical humanities coursework is associated with greater measured empathy in medical students. Americal Journal of Medicine. 2016;129(12):1334-7.

77. Muszkat M, Yehuda AB, Moses S, Naparstek Y. Teaching empathy through poetry: a clinically based model. Medical Education. 2013;44(5):503-.

78. Shapiro J, Morrison E, Boker J. Teaching empathy to first year medical students: evaluation of an elective literature and medicine course. Education for Health. 2004;17(1):73-84.

79. Wilby M. Teaching others to care: a case for using the humanities. International Journal for Human Caring. 2011;15(4):29-32.

80. Zazulak J, Sanaee M, Frolic A, Knibb N, Tesluk E, Hughes E, et al. The art of medicine: arts-based training in observation and mindfulness for fostering the empathic response in medical residents. Medical Humanities. 2017;43(3):192-8. 81. Bal PM, Veltkamp M. How Does Fiction Reading Influence Empathy? An Experimental Investigation on the Role of Emotional Transportation. PLOS ONE. 2013;8(1):e55341.

82. Hooker C. Understanding empathy: why phenomenology and hermeneutics can help medical education and practice. Medicine Health Care and Philosophy. 2015;18:541-52.

83. Simpkin AL, Schwartzstein RM. Tolerating uncertainty - the next medical revolution? The New England Journal of Medicine. 2016;375(18):1713-15.

84. Geller G, Faden RR, Levine D. Tolerance for ambiguity among medical students: implications for their selection, training and practice. Social Science \& Medicine. 1990;31(5):619-24.

85. Bentwich ME, Gilbey P. More than visual literacy: art and the enhancement of tolerance for ambiguity and empathy. BMC Medical Education. 2017;17(1):200.

86. Bates V, Bleakley A, Goodman S. Medicine, Health and the Arts: Approaches to the Medical Humanities: Routledge Chapman and Hall; 2013.

87. Cole T, Carlin N, Carson RA. Medical Humanities: an introduction.

Cambridge: Cambridge Press; 2015.

88. Crawford P, Brown B, Baker C, Tischler V, Adams B. Health Humanities. London: Palgrave Macmillan; 2015.

89. Monrouxe LV, Rees CE. Healthcare Professionalism: improving practice through reflections on workplace dilemmas. Oxford: John Wiley and Sons Ltd; 2017. 90. Peterkin A, Brett-MacLean P. Keeping Reflection Fresh: a practical guide for clinical educators: Kent State University Press; 2016.

91. Peterkin AD, Skorzewska A. Health Humanities in Post-Graduate Medical Education. Oxford: Oxford University Press; 2018. 


\section{University Library}

\section{- M M I E R R A A gateway to Melbourne's research publications}

Minerva Access is the Institutional Repository of The University of Melbourne

Author/s:

Harvey, P;Chiavaroli, N;Day, G

Title:

Arts and Humanities in Health Professional Education

Date:

2020

Citation:

Harvey, P., Chiavaroli, N. \& Day, G. (2020). Arts and Humanities in Health Professional Education. Nestel, D (Ed.). Reedy, G (Ed.). McKenna, L (Ed.). Gough, S (Ed.). Clinical Education for the Health Professions, (First), pp.1-18. Springer Singapore.

Persistent Link:

http://hdl.handle.net/11343/249853 